\section{A pilot study of one-session biofeedback training in pediatric headache}

S.W. Powers, PhD; M.J. Mitchell, PhD; K.C. Byars, PsyD; A.-L. Bentti, RN, MSN, CPNP; S.L. LeCates, RN, MSN, CFNP and A.D. Hershey, $M D, P h D$

Relaxation training and thermal biofeedback are promising treatments for pediatric headache..$^{1-5}$ This study evaluated the effectiveness of an hour-long, biofeedback-assisted relaxation training (BART) session within the context of a multidisciplinary pediatric headache center. The objectives were to determine whether peripheral body temperature (PBT) changes obtained during the training session (T1) could be maintained when measured at the child's subsequent follow-up clinic visit (T2), and to summarize headache perception and quality of life at T1 and T2.

Methods. Twenty children consecutively referred for BART received standard multidisciplinary treatment and BART based on headache presentation and developmental status. The sample consisted of 10 girls and 10 boys, with a mean age of 11.6 years $(\mathrm{SD}=2.2$ years). The sample was predominantly white $(95 \%)$. All children were clinically diagnosed with migraine, with $90 \%$ meeting International Headache Society criteria. The sample was representative of the general population of the headache center ${ }^{6}$ and those children referred for BART.

Children were taught age-appropriate skills in deep breathing, progressive muscle relaxation, and guided imagery. PBT was monitored via a computer-based biofeedback system. Children were encouraged to practice with an audio tape at least three times each week (for 2 weeks) and at headache onset. Thereafter, the children were instructed to perform relaxation regularly on their own.

PBT was measured at three time points: pretraining (PT), T1, and T2. At PT, PBT was measured before any relaxation training had occurred. At T1, PBT was measured before and after BART. At T2, PBT was assessed at the beginning of the clinic visit (prerelaxation) and 10 minutes after being instructed to "relax as you normally do" (postrelaxation). T2 data were collected at the child's first or second follow-up clinic visit after BART and before examination by members of the headache center team. The time from T1 to $\mathrm{T} 2$ averaged 150.7 days $(\mathrm{SD}=77.3$ days). Changes in PBT (PBT $\Delta$ ) were calculated for $\mathrm{T} 1$ and T2 by subtracting PBT at pretraining/ relaxation from PBT post-training/relaxation. For $85 \%$ of the sample ( $\mathrm{n}=17)$, we were also able to calculate PBT $\Delta$ at PT.

Results. Results show that children were not able to significantly increase their PBT before BART (mean PBT $\Delta$ at PT $=0.27$ ${ }^{\circ} \mathrm{F}$; SD $=0.70{ }^{\circ} \mathrm{F}$ ). However, once trained in BART, a positive change in PBT occurred at T1 (mean $=3.3^{\circ} \mathrm{F} ; \mathrm{SD}=2.5^{\circ} \mathrm{F}$ ) and $\mathrm{T} 2\left(\right.$ mean $\left.=3.7^{\circ} \mathrm{F} ; \mathrm{SD}=4.5^{\circ} \mathrm{F}\right)$. Within-subject $t$-tests showed that changes were significant from PT to T1 $(t=-4.087 ; p<0.01)$ and from PT to T2 $(t=-2.687 ; p<0.02)$. PBT changes were maintained from $\mathrm{T} 1$ to $\mathrm{T} 2(t=-0.427$; NS: $d f=19)$. Ninety percent of children at $\mathrm{T} 1$ and $95 \%$ at $\mathrm{T} 2$ were able to obtain a positive change in PBT.

Headache severity decreased from a mean of 5.0 (0 to 10 scale; $10=$ most pain) at T1 to 4.5 at T2. Average headache frequency decreased from 12.9 to 9.7 days/month, and duration also decreased from 6.9 to 5.2 hours. PBT $\Delta$ at T2 was significantly correlated with a decrease in headache frequency $(r=-0.45 ; p<$ 0.05 ). Seven children at T1 reported missing school owing to headaches compared with two children at T2. In general, $85 \%$ of parents reported that their child was functioning "better" at T2 as compared with $\mathrm{T} 1$.

Discussion. For most children, BART effects can be gained in the course of a 1-hour relaxation session, particularly when skills are taught within the context of a multidisciplinary clinic and in conjunction with standardized biobehavioral treatment. These skills can then be maintained with self-directed practice sessions. The one-session BART model offers a promising and reasonable alternative to traditional medical models that do not offer biofeedback training or traditional psychological models that offer intensive intervention to relatively few patients. The potential benefits of BART, in conjunction with lifestyle and pharmacologic treat- ments, ${ }^{7}$ include less frequent and less severe headaches and greater school attendance.

This study is limited by the small sample size, but the overwhelming response demonstrates the notable potential of onesession BART. The fact that one participant was unable to maintain PBT at follow-up assessment suggests that standardized 1-hour BART may be less effective for atypical cases. Children were taught to use biofeedback in conjunction with traditional pharmacologic treatments, and these pharmacologic treatments likely account for some of the patients' improvements in headache quality and daily functioning. The sustained responsiveness of BART (T1 to T2), however, suggests that BART may also play an important role. As researchers and clinicians acknowledge the benefits of BART in pediatric populations, future studies should be aimed at understanding how BART may be used most efficiently within home- and clinic-based settings.

From the Divisions of Psychology (Drs. Powers, Mitchell, and Byars) and Neurology (A.-L. Bentti, S. LeCates, and Dr. Hershey), Cincinnati Children's Hospital Medical Center; and the University of Cincinnati College of Medicine (Drs. Powers and Hershey), $\mathrm{OH}$.

Received June 9, 2000. Accepted in final form August 29, 2000.

Address correspondence and reprint requests to Dr. Scott W. Powers, Cincinnati Children's Hospital Medical Center, Division of Psychology, CH-1, 3333 Burnet Avenue, Cincinnati, OH 45229-3039; e-mail: scottpowers@chmcc.org

Copyright $\odot 2001$ by AAN Enterprises, Inc.

\section{References}

1. Hermann C, Kim M, Blanchard EB. Behavioral and prophylactic intervention studies of pediatric migraine: an exploratory meta-analysis. Pain 1995;60:239-255.

2. McGrath PJ, Reid GJ. Behavioral treatment of pediatric headache. Pediatr Ann 1995;24:486-491

3. Duckro PN, Cantwell-Simmons E. A review of studies evaluating biofeedback and relaxation training in the management of pediatric headache. Headache 1989;29:428-433.

4. Reid GJ, McGrath PJ. Psychological treatments for migraine. Biomed Pharmacother 1996;50:58-63.

5. Burke EJ, Andrasik F. Home vs clinic-based treatment for pediatric migraine: results of treatment through one-year follow-up. Headache 1989;29:434-440.

6. deGrauw TJ, Hershey AD, Powers SW, Bentti AL. Diagnosis of migraine in children attending a pediatric headache clinic. Headache 1999;39: 481-485.

7. Hershey AD, Powers SW, Bentti AL, deGrauw TJ. Effectiveness of amitriptyline as a prophylactic treatment for pediatric migraines. Headache 2000;40:539-549.

\section{Postictal coughing and noserubbing coexist in temporal lobe epilepsy}

Richard Wennberg, $M D, F R C P(C)$

Postictal coughing (PIC) has been described as a clinical localizing sign more common in temporal than extratemporal epilepsy. ${ }^{1,2}$ Postictal noserubbing (PIN) is another clinical sign indicative of temporal lobe seizure onset. ${ }^{3-6}$ PIN is thought to occur in response to increased nasal secretions caused by ictal activation of the central autonomic pathways. ${ }^{3,4,6}$ Because PIC could also be a reaction to increased respiratory secretions ${ }^{3}{ }^{3}$ this study sought to determine whether PIC and PIN co-occurred in the same patients. If so, it would define a subset of patients with temporal lobe epilepsy whose seizures preferentially induce secretions throughout the nasotracheobronchial tree.

Patients and methods. As part of a larger prospective study analyzing the electroclinical features of PIN,${ }^{6}$ episodes of PIC were documented in a group of 75 consecutive patients with temporal lobe epilepsy investigated in an epilepsy monitoring unit between April 1997 and April 2000. Coughing that occurred simultaneously with electrographic ictal offset or within a few seconds (1 to 3 ) of offset was included along with PIC for the purposes of this study.

Patients were classified as mesial temporal or neocortical temporal based on the MRI or pathologic findings or, in four cases, based on the results of intracranial EEG recording. Thirteen pa- 


\section{Neurology}

\section{A pilot study of one-session biofeedback training in pediatric headache}

S. W. Powers, M. J. Mitchell, K. C. Byars, et al.

Neurology 2001;56;133

DOI 10.1212/WNL.56.1.133

\section{This information is current as of January 9, 2001}

Updated Information \& Services

References

Subspecialty Collections

Permissions \& Licensing

Reprints including high resolution figures, can be found at: http://n.neurology.org/content/56/1/133.2.full

This article cites 7 articles, 0 of which you can access for free at: http://n.neurology.org/content/56/1/133.2.full\#ref-list-1

This article, along with others on similar topics, appears in the following collection(s):

All Headache

http://n.neurology.org/cgi/collection/all_headache All Pediatric

http://n.neurology.org/cgi/collection/all_pediatric Migraine

http://n.neurology.org/cgi/collection/migraine

Information about reproducing this article in parts (figures,tables) or in its entirety can be found online at:

http://www.neurology.org/about/about_the_journal\#permissions

Information about ordering reprints can be found online:

http://n.neurology.org/subscribers/advertise

Neurology $®$ is the official journal of the American Academy of Neurology. Published continuously since 1951, it is now a weekly with 48 issues per year. Copyright . All rights reserved. Print ISSN: 0028-3878. Online ISSN: 1526-632X.

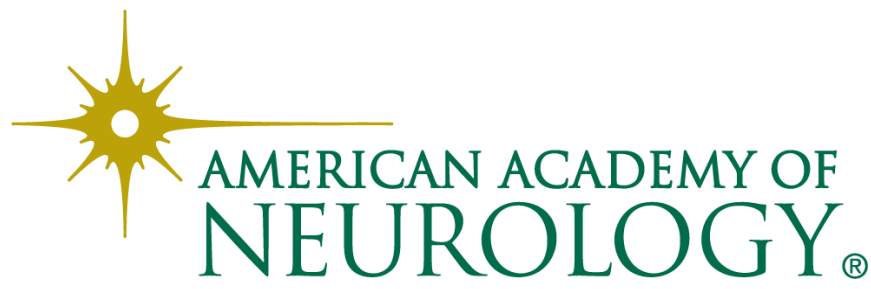

